\title{
Are adolescent elite athletes less psychologically distressed than controls? A cross-sectional study of 966 Norwegian adolescents
}

This article was published in the following Dove Press journal:

Open Access Journal of Sports Medicine

Jan H Rosenvinge'

Jorunn Sundgot-Borgen²

Gunn Pettersen ${ }^{3}$

Marianne Martinsen ${ }^{4}$

Annett Victoria Stornæs ${ }^{2}$

Anne Marte Pensgaard ${ }^{5}$

'Department of Psychology, Faculty of Health Sciences, UiT - The

Arctic University of Norway,

Troms $\varnothing$, Norway; ${ }^{2}$ Department

of Sports Medicine, Norwegian

School of Sport Sciences, Oslo,

Norway; ${ }^{3}$ Department of Health and

Caring Sciences, Faculty of Health

Sciences, University of Tromsø,

Tromsø, Norway; ${ }^{4}$ Department of

Mathematics, Natural Sciences, and

Physical Education, Inland Norway

University of Applied Sciences, Hamar,

Norway; ${ }^{5}$ Department of Coaching

and Psychology, Norwegian School of

Sports Science, Oslo, Norway
Correspondence: Jan H Rosenvinge Department of Psychology, UiT - The Arctic University of Norway, Postboks 6050 Langnes, N-9037 Tromsø, Norway Email jan.rosenvinge@uit.no
Introduction: Psychological distress is increasing among adolescents and clusters with other mental health problems such as eating problems. The aim of this study was to investigate the prevalence of psychological distress among young elite athletes and age-matched controls and whether prevalence figures may be attributed to perfectionism and eating problems.

Methods: First-year athletes from all Norwegian elite sport high schools $(n=711)$ and 500 students from randomly selected ordinary high schools were eligible for this cross-sectional study. In total, 611 athletes and 355 student controls provided self-report data about psychological distress, perfectionism, and eating problems (ie, body dissatisfaction and a drive for thinness), as well as their physical training/activity.

Results: A significantly higher proportion of controls scored above the cutoff point for marked psychological distress. Physical activity above the recommended levels for this age group predicted psychological distress among the controls, while the opposite was found in the student elite athlete sample. In both samples, perfectionistic concerns, ie, concern over mistakes, predicted overall psychological distress. However, among elite athletes, perfectionistic concerns were particularly associated with clinically significant psychological distress. Moreover, the impact of eating problems was negligible.

Conclusion: Results from this study highlight the need to target the maladaptive perfectionistic concerns to prevent psychological distress among young athletes as well as among their agematched nonathlete counterparts.

Keywords: psychological distress, competitive athletes, perfectionism

\section{Introduction}

Participation in physical activity and sports can promote mental and physical wellbeing as well as functional coping with stress. ${ }^{1,2}$ However, it is also a fact that, for some people, competitive sports may cause anxiety and distress..$^{3-5}$ The International Olympic Committee has elicited a consensus statement ${ }^{6}$ raising concerns about such possible negative side effects of elite sport participation during the vulnerable adolescent phase of life. Because of this concern, the current study set out to investigate the prevalence and selected correlates of psychological distress between a representative sample of elite adolescent athletes and age-matched general population.

Whether psychological distress elicits positive or negative consequences depends on the magnitude of stress and the interpretation of a stressing event. ${ }^{7}$ Positive 
consequences are likely if the individual has, or is convinced about having the necessary resources to manage the stressor. ${ }^{7}$ Hence, stress handled well can improve or promote daily life functioning as well as sport performances. ${ }^{8}$ However, lack of such a positive belief or expectation may lead to negative consequences and cause distress, which usually comprises unpleasant and activating feelings such as sadness, distraction and worry. Even among athletes who are exposed to health potentials and benefits from physical training, psychological distress may develop into more serious psychological disorders $^{9}$ such as anxiety, depression and eating disorders. ${ }^{10}$ In addition, negative expectations may raise the risk of burnout and dropout from sports. ${ }^{11}$

Large-scale representative studies of the general adolescent population in Scandinavia have revealed a consistent pattern of increased distress ${ }^{12-14}$ across publication years and with increasing age of the adolescent cohort. Such consistency has not been established for adolescent athletes, ${ }^{5-9}$ and one may then assume that sport participation indeed promotes well-being and reduces the level of distress. The reliability of this assumption is, however, challenged by methodological issues, because many studies suffer from poor sample representativity and low statistical power. In addition, most studies fail to use matched comparison samples. The validity of the assumption is challenged by investigating how important psychological factors may mutually interact and operate on both a personal and a sport-specific arena in explaining the variation in distress among both athletes and nonathletes.

Perfectionism reflects a commitment to high standards combined with a tendency to critically appraise performance accomplishments. ${ }^{15-17}$ To achieve success, for instance, in competitive sports, one needs to strive towards achieving "perfection." Such a perfectionistic striving is productive and health promoting if it corresponds to a realistic selfevaluation of the sum of external and personal resources to reach the goal. ${ }^{16,18}$ Access to sufficient resources is thus a common denominator in both the functional coping with stress and how the individual handles demands in his or her sport and in life in general. Perfectionistic strivings are thus conceived as desirable, because they are associated with perceiving stressful situations as a positive challenge rather than a threat. In return, strivings may act as a buffer against anxiety by the capacity to enhance confidence and personal control. ${ }^{19,20} \mathrm{~A}$ far more problematic dimension of perfectionism, however, is "perfectionistic concerns." Such concerns are characterized by a reaching out for a goal driven by a fear of failure, where chasing the "best" performance represents a strategy to avoid criticism and self-blame of not keeping up with personal or external standards of performance. ${ }^{20-23}$ Perfectionistic concerns are highly prevalent among females ${ }^{24}$ and may contribute in explaining variations in distress among athletes. $^{25-28}$

Eating problems are more clinically severe than normal variations in eating patterns, and body concern, but less severe than conditions satisfying one of the formal eating disorder diagnoses. ${ }^{29}$ Eating problems affect about $30 \%$ of adolescent girls in the general population. ${ }^{30}$ Even higher percentages have been reported among athletes, notably among those engaged in sports where requirements for success comprise leanness and a particular body appearance. ${ }^{31,32}$

Perfectionistic concerns, labeled as "clinical perfectionism," appear as maintaining factors in cognitive models of eating disorders, ${ }^{29}$ and in meta-analyses ${ }^{33}$ and subsequent studies ${ }^{34}$ such perfectionism has also been consistently identified as a risk factor for eating disorders.

The current study was set out to investigate 1) the prevalence of psychological distress among male and female adolescent elite athletes and age-matched controls, and 2) whether perfectionistic concerns and eating problems can account for the variation in psychological distress among male and female adolescent elite athletes and age-matched controls. We expected to find a "higher" level of distress among nonathlete adolescents but that perfectionistic concerns and eating problems will account for variations in psychological distress among both controls and athletes, despite possible health-promoting effects of sport participation.

\section{Subjects and methods Participants}

The inclusion criteria were as follows: birth date in 1992; being enrolled as a first-year student at one of the Norwegian elite sport high schools (athletes) or at one of the two randomly selected high schools in Buskerud county in Norway (controls). Exclusion criteria were as follows: birth date later than 1992; parental consent not obtained, or grossly incomplete study questionnaires submitted. Norwegian elite sport high schools are selective, private and public high schools designed for highly talented athletes. The schools provide the best possible conditions, combining education and sports, and give athletes the opportunities to compete on a national or an international level and at the same time acquire high school graduation. We selected the student control group from Buskerud county, because its population is representative of the country population on most sociodemographic variables. 
Of the 711 athletes and 500 student controls who were originally approached, 34 athletes and 79 student controls were excluded (due to age: 29 athletes and 60 controls; did not obtain parental consent: five athletes and 19 controls). Of the remaining 677 athletes and 421 controls, 66 athletes and 66 controls did not participate for unknown reasons. This resulted in a final sample of 611 athletes (390 male and 221 female athletes) and 355 controls (199 male and 156 females) with a response rate of $86 \%$ and $71 \%$, respectively. Because the total population from all the national elite sport high schools was included with a high response rate, statistical power calculations were not performed.

\section{Individual and team sport participation}

The sample of athletes represented all kinds of individual and team sports. In the control group, 39\% $(\mathrm{n}=139 ; 93$ males and 46 females) reported being involved in organized sports in their leisure time. An account of the number of sports students and controls participated in according to a classification of sports groups is summarized in Table 1.

The Norwegian Committee for Medical and Health Sciences Research approved this study. The authors report that all the included subjects and their parents gave their written informed consent to participate and that the research was conducted according to the Declaration of Helsinki.

\section{Assessment procedures}

All participants completed three standardized questionnaires measuring psychological distress, facets of disordered eating and perfectionism. In addition, questions about physical activity and training volume were included. The participants completed all questions in the presence of one of the research group members.

\section{Hopkins' Symptom Checklist (HSCL-5): short version measuring psychological distress}

The short version of HSCL-5 is a five-item scale designed to measure psychological distress in terms of worry, anxiety and dysphoria. All items are scored on a 4-point scale ranging from $1=$ "not at all" to $4=$ "extremely." The item score is calculated by dividing the total score of the number of items answered (ranging from 1 to 4 ), and a cutoff score of $>2$ indicates psychological distress. ${ }^{35}$ The HSCL-5 is reliable; it significantly correlates with the original instrument ${ }^{36}$ and shows good construct validity. The brief version's positive predictive value makes it feasible in population-based multicomponent studies where space can be a critical factor. ${ }^{35}$ In the current study, the internal consistency is highly satisfactory (Cronbach's $\alpha=0.87$ ).

\section{Frost Multidimensional Perfectionism Scale (F-MPS)}

A Norwegian version ${ }^{37}$ of the F-MPS ${ }^{16}$ assesses degrees of perfectionism and distinguishes between perfectionistic strivings and perfectionistic concern. It consists of 29 items scored on a 5-point scale ranging from "strongly disagree" to "strongly agree." These items are divided into five subscales,

Table I Classification of 50 different sports into weight-sensitive and less weight-sensitive sports

\begin{tabular}{|c|c|c|c|c|c|c|}
\hline \multicolumn{4}{|c|}{$\begin{array}{l}\text { Weight-sensitive sports }(n=197 ; n=162 \text { athletes, } \\
n=35 \text { controls) }\end{array}$} & \multicolumn{3}{|c|}{$\begin{array}{l}\text { Less weight-sensitive sports }(n=552 ; n=449 \text { athletes, } \\
n=103 \text { controls) }\end{array}$} \\
\hline \multirow{2}{*}{$\begin{array}{l}\text { Esthetic } \\
(n=20)\end{array}$} & \multirow{2}{*}{$\begin{array}{l}\text { Weight } \\
\text { class } \\
(n=\mid 7)\end{array}$} & \multicolumn{2}{|c|}{ Gravitational } & \multirow{2}{*}{$\begin{array}{l}\text { Ballgames } \\
(n=4 I I)\end{array}$} & \multirow{2}{*}{$\begin{array}{l}\text { Power/technical } \\
(n=68)\end{array}$} & \multirow{2}{*}{$\begin{array}{l}\text { High mass } \\
(n=73)\end{array}$} \\
\hline & & $\begin{array}{l}\text { Technical } \\
(n=\mid 3)\end{array}$ & $\begin{array}{l}\text { Endurance } \\
(n=\mid 47)\end{array}$ & & & \\
\hline Dancing & Judo & High jump & Cycling & Table tennis & Sprinting & Alpine skiing \\
\hline \multirow[t]{12}{*}{ Gymnastics } & Karate & Ski jump & Nordic combined & Tennis & Golfing & Ice hockey \\
\hline & Taekwondo & Long jump & cross-country skiing & Basketball & Fencing & Hammer \\
\hline & Boxing & Triple jump & Biathlon & Soccer & Motor sports & Discus \\
\hline & Jiu-jitsu & Hurdle & Paddling & Handball & Show jumping & Javelin \\
\hline & & Heptathlon & Orienteering & Floorball & Freestyle skiing & \\
\hline & & Decathlon & Middle- and long- & Volleyball & "new school" & \\
\hline & & & distance running & Beach & Mogul skiing & \\
\hline & & & Dog-sled racing & volleyball & Sailing & \\
\hline & & & BMX cycling & & Shooting & \\
\hline & & & Mountain biking & & Snowboarding & \\
\hline & & & Rowing/sculling ${ }^{\mathrm{a}}$ & & Chess & \\
\hline & & & Swimming & & & \\
\hline
\end{tabular}

Note: Adapted from Martinsen and Sundgot-Borgen. ${ }^{32}$ a $\mathrm{A}$ light weight. 
used in the current study, ie, concern over mistakes, doubts about actions, parental expectations, parental criticism and personal standards. All subscales except the "personal standards" subscale are measures of perfectionistic concerns. ${ }^{16,38}$ In the current study, the internal consistency (Cronbach's $\alpha$ ) of all subscales was highly satisfactory ranging from 0.70 to 0.86 .

\section{The Eating Disorder Inventory-2 (EDI-2) measuring eating problems}

The EDI-2 is a 91-item, 6-point self-report measure assessing eating problems, ${ }^{39}$ and it has been validated in Scandinavian general and clinical populations. ${ }^{40}$ In the current study, we have used two of its subscales, ie, drive for thinness and body dissatisfaction, as both subscales may effectively identify athletes with subclinical and clinical eating disorders. ${ }^{41}$ In the current study, the internal consistency (Cronbach's $\alpha$ ) for these subscales was 0.76 and 0.78 , respectively.

\section{Physical training and physical activity}

The number of training hours for the athletes $(n=611)$ and student controls participating in organized sports $(n=139)$ was self-reported on an interval scale and was the average amount of physical training per week for the past 4 weeks.
The student control group who did not participate in any organized sports $(n=215)$ was asked how many hours they had been physically active per week for the past 4 weeks.

The majority of the athletes trained $>11$ hours/week (Table 2). Therefore, the number of hours with physical training per week was dichotomized to $\leq 10$ hours and $\geq 11$ hours. For the controls, physical activity per week was dichotomized regarding the recommended weekly physical activity level for this age group, ie, $\leq 6$ hours and $\geq 7$ hours a week.

\section{Statistical analyses}

Independent variables that significantly correlated with the HSCL measure of psychological distress were used in a linear and a stepwise logistic regression analysis. These analyses were performed for the athlete and control groups separately, because the level of physical activity was very different in the two samples. Step 1 in the logistic regression analysis comprised variables measuring physical activity as well as the perfectionism scales measuring facets of perfectionistic striving (ie, personal standards) and perfectionistic concerns (ie, concern about mistakes, parental expectations, parental criticism and doubts about actions). The scales measuring eating problems (ie, drive for thinness and body dissatisfaction) were entered in step 2, and finally, gender in step 3 .

Table 2 Descriptive variables for males, females and in total

\begin{tabular}{|c|c|c|c|c|c|}
\hline \multirow[t]{2}{*}{ Variables } & \multicolumn{2}{|l|}{ Male } & \multicolumn{2}{|l|}{ Female } & \multirow{2}{*}{$\frac{\text { Total }}{n=966}$} \\
\hline & $\begin{array}{l}\text { Athletes } \\
(n=90)\end{array}$ & $\begin{array}{l}\text { Control } \\
(n=99)\end{array}$ & $\begin{array}{l}\text { Athletes } \\
(n=22 I)\end{array}$ & $\begin{array}{l}\text { Control } \\
(n=56)\end{array}$ & \\
\hline Height (cm), mean (SD) & $179.9(6.8)$ & $180.3(6.8)$ & $168.5(6.0)$ & $167.2(6.1)$ & NA \\
\hline Weight (kg), mean (SD) & $70.8(9.0)$ & $71.5(11.6)$ & $60.2(6.8)$ & $59.4(9.3)$ & NA \\
\hline BMI $\left(\mathrm{kg} / \mathrm{m}^{2}\right)$, mean $(\mathrm{SD})$ & $21.8(2.0)$ & $22.0(3.2)$ & $21.2(2.1)$ & $21.2(3.2)$ & NA \\
\hline Organized sport participation, n (\%) & $390(100)$ & $93(46.7)$ & $221(100)$ & $46(29.5)$ & $750(77.6)$ \\
\hline \multicolumn{6}{|c|}{ Sport groups (athletes, $n=6 \mid 1$; controls in orgnaized sports $n=138$ ) } \\
\hline Weight-sensitive sports, n (\%) & $102(26.2)$ & $19(20.7)$ & $60(27.1)$ & $16(34.7)$ & $197(26.3)$ \\
\hline Less weight-sensitive sports, n (\%) & $288(73.8)$ & $73(79.3)$ & $161(72.9)$ & $30(65.2)$ & $552(73.7)$ \\
\hline Training volume $\left(\mathrm{n}=738^{\mathrm{b}}\right) \geq 1 \mathrm{I}$ hours/week, $\mathrm{n}(\%)$ & $314(82.4)$ & $49(24.6)$ & $178(8 \mid .3)$ & $17(10.9)$ & $558(57.8)$ \\
\hline Physical activity $\left(\mathrm{n}=198^{\circ}\right) \geq 7$ hours/week, $\mathrm{n}(\%)$ & NA & $57(28.6)$ & NA & $42(26.9)$ & NA \\
\hline F-MPS mean (SD) ${ }^{d}$ & $2.5(0.6)$ & $2.4(0.9)$ & $2.5(0.7)$ & $2.4(0.9)$ & $2.45(0.7)$ \\
\hline F-MPS, personal standards e,f & $3.3(0.8)$ & $2.9(1.0)$ & $3.1(0.8)$ & $2.8(1.0)$ & $3.06(0.9)$ \\
\hline F-MPS, concern over mistakes ${ }^{f}$ & $2.4(0.8)$ & $2.3(1.0)$ & $2.5(0.9)$ & $2.2(0.9)$ & $2.34(0.9)$ \\
\hline F-MPS, doubt about actions ${ }^{8}$ & $2.7(0.8)$ & $2.6(0.8)$ & $3.0(0.8)$ & $2.8(1.0)$ & $2.78(0.9)$ \\
\hline F-MPS, parental expectations ${ }^{e, f}$ & $1.9(0.8)$ & $2.3(1.0)$ & $1.9(0.9)$ & $2.2(1.1)$ & $2.04(1.0)$ \\
\hline F-MPS, parental criticisme & $1.9(0.7)$ & $2.2(1.0)$ & $1.9(0.8)$ & $2.1(I . I)$ & $1.96(0.9)$ \\
\hline HSCL-5, mean $(S D)^{f g}$ & $0.6(0.6)$ & $0.7(0.9)$ & $0.9(0.8)$ & $1.2(1.0)$ & $0.80(0.8)$ \\
\hline EDI-2-DT, total, mean (SD) ${ }^{\mathrm{e}, \mathrm{f}}$ & $0.7(1.9)$ & I.3 (2.6) & $2.7(4.3)$ & $5.3(5.8)$ & $2.04(3.9)$ \\
\hline EDI-2-BD, total, mean (SD) ${ }^{\mathrm{e}, \mathrm{f}}$ & $2.4(3.3)$ & 4.I (4.6) & $6.9(6.8)$ & $10.6(8.0)$ & $5.12(6.2)$ \\
\hline
\end{tabular}

Notes: ${ }^{a}$ Controls who are participating in organized sports $(n=139)$ are doing this outside school, and the performance levels are low to medium ( $\mathrm{n}=\mathrm{I}$ missing). ${ }^{\mathrm{b}}$ Missing $(n=12)$. Missing $(n=17)$. Training volume $\geq 11$ hours reported by athletes $(n=611)$ and controls $(n=139)$ who participated in organized sports. Physical activity $\geq 7$ hours of physical activity per week as reported by controls who did not participate in organized sports $(n=215)$. ${ }^{d} p<0.05$ female athletes compared with female controls. ${ }^{e} p<0.01$ male athletes compared with male controls, ${ }^{f} p<0.01$ female athletes compared with female controls. ${ }^{g} p<0.05$ male athletes compared with male controls.

Abbreviations: BD, body dissatisfaction; BMI, body mass index; DT, drive for thinness; EDI-2, Eating Disorder Inventory-2; F-MPS, Frost Multidimensional Perfectionism Scale; HSCL, Hopkins' Symptom Checklist; NA, not applicable. 


\section{Results}

\section{Subject characteristics}

All student elite athletes and the student control group were 15-16 years old by the data collection time. They did not differ in weight (BMI: $21.2 \mathrm{~kg} / \mathrm{m}^{2}$ for athletes versus BMI $21.9 \mathrm{~kg} / \mathrm{m}^{2}$ for controls). An overview of the prevalence of participants in various sports, and information about basic demographics and the mean scores on the psychological assessments are presented in Tables 1 and 2, respectively.

\section{Prevalence of psychological distress}

As summarized in Table 3, a significantly $(p<0.000)$ higher proportion of controls scored above the cut point for marked psychological distress. In addition, a higher proportion of females scored above the cut point irrespective of being an athlete or a control. As for the mean HSCL-5, the controls displayed significantly $(p<0.000)$ higher scores $(0.95$; SD $0.97)$ compared with athletes $(0.71$; SD 0.71$)$. However, the effect size (Hedge's $g$ ) was small (ie, 0.29). For the mean score, the higher score for controls (4.74; SD 4.87) versus athletes (3.50; SD 3.50) yielded a higher effect size, ie, 0.62.

\section{Multivariate analyses of variables accounting for psychological distress}

Facets of perfectionism and eating problems correlated significantly with psychological distress $(p<0.001)$ and ranged from 0.30 to 0.43 , and these facets were thus used in the multivariate analyses.

\section{Elite student athletes}

Psychological distress above the cutoff score was predicted by the perfectionistic concerns: concern over mistakes and doubt about actions. These dysfunctional facets yielded a

Table 3 Prevalence of psychological distress (HSCL-5 $\geq 2.0$ ) across sample and gender

\begin{tabular}{|c|c|c|c|c|c|c|}
\hline & \multirow[t]{2}{*}{ HSCL score } & \multicolumn{2}{|c|}{$\begin{array}{l}\text { Student elite } \\
\text { athletes }\end{array}$} & \multicolumn{2}{|c|}{$\begin{array}{l}\text { Student } \\
\text { controls }\end{array}$} & \multirow[t]{2}{*}{$p$-value } \\
\hline & & $\%$ & $\mathbf{N}$ & $\%$ & $\mathbf{N}$ & \\
\hline \multirow[t]{2}{*}{ Male } & HSCL-5 <2.0 & 96.4 & 370 & 85.4 & 169 & 0.000 \\
\hline & HSCL-5 2.0-4.0 & 3.6 & 14 & 14.6 & 29 & \\
\hline \multirow[t]{2}{*}{ Female } & HSCL-5 $<2.0$ & 86.8 & 191 & 75.6 & 118 & 0.005 \\
\hline & HSCL-5 2.0-4.0 & 13.2 & 29 & 24.4 & 38 & \\
\hline$p$-value & & 0.000 & & 0.021 & & \\
\hline \multirow[t]{2}{*}{ Total } & HSCL-5 <2.0 & 92.9 & 561 & 81.1 & 287 & 0.000 \\
\hline & HSCL-5 2.0-4.0 & 7.1 & 43 & 18.9 & 67 & \\
\hline$p$-value & & 0.000 & & 0.000 & & \\
\hline
\end{tabular}

Note: Missing student elite athletes $(n=7)$ and student controls $(n=1)$. Abbreviation: HSCL, Hopkins' Symptom Checklist. fourfold risk of significant psychological distress (Table 4) and also explained most variance in total distress scores (Table 5). Some variance in total distress scores was also accounted for by the facet "parental criticism" (Table 5). Moreover, "lower" levels of physical activity and being a female predicted overall distress scores as well as distress scores above the cut point. Finally, eating problems, ie, body dissatisfaction and drive for thinness, predicted total distress scores but not distress above the cut point. "Parental expectations" as well as the positive perfectionism facet "personal standards" did not significantly contribute in explaining variations in total HSCL-5.

\section{Student controls}

"Doubts about action" predicted overall distress, but not distress above the cut point for severity (Tables 4 and 5). Moreover, "parental criticism" was highly predictive of total distress but not distress above the cutoff score. Unlike athletes, however, "concern about mistakes" was not related to total distress scores (Table 5); however, such concerns were also, in this sample, related to an almost tripled risk for highly elevated distress (Table 4). Unlike for athletes, the effect of eating problems was nonsignificant related to total distress, yet body dissatisfaction yielded slightly elevated risk of marked distress (odds ratio 1.08; 95\% CI 1.10-4.34; Table 4). In addition, unlike for athletes, perfectionistic striving predicted lower cutoff scores on the HSCL-5 but not a lower HSCL-5 total score.

Table 4 Final step in logistic regression models predicting above (value $=\mathrm{I}$ ) the HSCL-5-cutoff scores for psychological distress among student controls and student elite athletes

\begin{tabular}{|c|c|}
\hline Samples & Odds ratio \\
\hline \multicolumn{2}{|l|}{ Student controls } \\
\hline Concern over mistakes & $2.88(95 \% \mathrm{Cl}$ I.54-5.38) \\
\hline Body dissatisfaction & $1.08(95 \% \mathrm{Cl}$ I. I0-4.34) \\
\hline Personal standards & $0.53(95 \% \mathrm{Cl} 0.3 \mathrm{I}-0.9 \mathrm{I})$ \\
\hline Time per week in physical activity & $2.18(95 \% \mathrm{Cl}$ I. $10-4.37)$ \\
\hline \multicolumn{2}{|l|}{$(0=0-6$ hours, $I=\geq 7$ hours $)$} \\
\hline Model $X^{2} /$ Cox and Snell $R^{2}$ & $70.96 * / 0.20$ \\
\hline \multicolumn{2}{|l|}{ Student elite athletes } \\
\hline Doubt about actions & $4.39(95 \% \mathrm{Cl} 2.24-8.62)$ \\
\hline Concern over mistakes & $4.0 \mathrm{I}(95 \% \mathrm{Cl}$ I.88-8.57) \\
\hline Gender $($ male $=0)$ & $2.96(95 \% \mathrm{Cl}$ ।.22-7.19) \\
\hline Organized physical training $(\leq 10$ hours, past & $0.4 \mathrm{I}(95 \% \mathrm{Cl} 0.17-0.96)$ \\
\hline \multicolumn{2}{|l|}{4 weeks $=I, \geq I I$ hours $=2$ ) } \\
\hline Model $X^{2} /$ Cox and Snell $R^{2}$ & $45.07 * / 0.37$ \\
\hline
\end{tabular}

Note: $* p<0.000$

Abbreviation: HSCL, Hopkins' Symptom Checklist. 
Table 5 Multiple regression analyses explaining variations in sum HSCL-5 scores on psychological distress for elite athletes and controls

\begin{tabular}{|c|c|c|c|c|c|}
\hline Samples & B & SE B & $\beta$ & t & $p$ \\
\hline \multicolumn{6}{|l|}{ Student controls: $F(d f I, 9)=\mid I .8 I, p<0.000$. Adjusted $R^{2}=0.42$} \\
\hline Constant & -5.63 & 1.70 & & -3.31 & 0.001 \\
\hline Parental criticism & 2.26 & 0.65 & 0.48 & 3.50 & 0.001 \\
\hline Doubts about action & 1.09 & 0.55 & 0.19 & 1.99 & 0.05 \\
\hline Gender $($ males $=I$, females $=2$ ) & 1.80 & 0.77 & 0.18 & 2.33 & 0.02 \\
\hline Concern about mistakes & 0.57 & 0.64 & 0.10 & 0.89 & ns \\
\hline Body dissatisfaction & 0.07 & 0.07 & 0.10 & 1.04 & ns \\
\hline Drive for thinness & 0.09 & 0.11 & 0.08 & 0.86 & ns \\
\hline Hours of physical training, past 4 weeks* & 0.24 & 0.30 & 0.06 & 0.79 & ns \\
\hline Parental expectations & -0.40 & 0.56 & -0.09 & -0.71 & ns \\
\hline Personal standards & -0.65 & 0.45 & -0.13 & -1.45 & ns \\
\hline \multicolumn{6}{|l|}{ Student elite athletes: $F(d f I, 9)=40.26, p<0.000$. Adjusted $R^{2}=0.37$} \\
\hline Constant & -2.63 & 0.86 & & -3.05 & 0.000 \\
\hline Concern about mistakes & 1.18 & 0.21 & 0.28 & 5.61 & 0.000 \\
\hline Doubts about action & 1.16 & 0.16 & 0.27 & 7.05 & 0.000 \\
\hline Gender $($ males $=I$, females $=2$ ) & 0.86 & 0.27 & 0.12 & 3.22 & 0.001 \\
\hline Drive for thinness & 0.12 & 0.05 & 0.11 & 2.61 & 0.01 \\
\hline Body dissatisfaction & 0.06 & 0.03 & 0.09 & 2.06 & 0.04 \\
\hline Parental criticism & 0.42 & 0.21 & 0.09 & 1.94 & 0.05 \\
\hline Hours of physical training, past 4 weeks $(\leq 10$ hours $=I, \geq I I$ hours $=2$ ) & -0.75 & 0.30 & -0.08 & 2.53 & 0.01 \\
\hline Personal standards & -0.15 & 0.18 & -0.04 & -0.83 & ns \\
\hline Parental expectations & -0.26 & 0.19 & -0.06 & -1.34 & ns \\
\hline
\end{tabular}

Note: *Hours of physical training over the past 4 weeks for the controls is specified as $\leq 5$ hours $=1,6-10$ hours $=2,11-15$ hours $=3,16-20$ hours $=5 \geq$ hours $=5$. Abbreviations: HSCL, Hopkins' Symptom Checklist; ns, not significant.

\section{Discussion}

\section{Prevalence of psychological distress among athletes and controls}

The first aim of this study was to determine the prevalence of psychological distress among young elite athletes compared with general population controls. Using the HSCL-5 as an indicator, we expected a high level of distress among nonathletes. This prediction was supported, as more than twice as many controls scored above the cutoff for significant psychological distress. By contrast, only just over $3 \%$ of the male athletes reported higher levels of psychological distress (Table 3). The current results echo another representative Norwegian study ${ }^{42}$ among 15 -year-old girls, which reported almost an identical proportion (25.6\%) scoring above the cut point on the HSCL-5 as in the female controls included in the current study. Hence, the current results lend no support to a notion that young elite athletes are more prone to experiencing psychological distress, but rather, echo previous findings ${ }^{5}$ that participation in elite sport is unrelated to elevated levels of psychological distress.

Social and cognitive factors may explain why athletes report less psychological distress than age-matched controls. First, sport participation implies a structuring of leisure time and a close contact with supportive adults that can be beneficial to adolescent mental health ${ }^{43}$ notably in reducing the risk for anxiety and depression. ${ }^{44}$ Second, young athletes may translate constructive strategies to manage stress related to sport performance and competitions into other contexts in their lives. ${ }^{2}$ By contrast, elite "adult" athletes seem to experience the same level of mental health problems as the general population..$^{9,45}$

\section{Variables associated with psychological distress among athletes versus controls}

The second aim was to investigate whether perfectionistic concerns and eating problems can account for the variation in psychological distress among male and female adolescent elite athletes and age-matched controls. In this study, we expected that eating problems and perfectionistic concerns accounted for variations in psychological distress among both controls and athletes.

Overall, compared with perfectionistic concerns, the unique contribution of eating problems only contributed marginally to account for psychological distress. It has been argued that adolescents stand out as vulnerable for developing eating disorders as the risk of such disorders is consistently 
related to body dissatisfaction and perfectionism. ${ }^{33}$ In the current study, however, it is noteworthy that body dissatisfaction only marginally explained marked distress among the controls (Table 4).

Neither "body dissatisfaction" nor a "drive for thinness" predicted marked psychological distress among athletes. Such a finding serves to temper the clinical importance of the high prevalence of eating problems previously reported among athletes. ${ }^{32}$ It has been argued ${ }^{46}$ that adolescent athletes may not experience marked psychological distress related to eating and physical appearance because they may come closer to an "ideal" of physical perfection than nonathletes. Closeness to ideals may then explain the modest explanatory power of drive for thinness and body dissatisfaction related to total distress. Thus, being an athlete may protect against the body dissatisfaction among nonathletes elicited by distress related to normal physical changes during adolescence. ${ }^{47}$

In general, the expectation with respect to perfectionism was supported. Thus, "doubt about actions" accounted for variations in overall distress scores in both samples. The risk of marked distress was almost threefold higher among controls and fourfold higher among athletes. This raised risk aligns with previous studies, ${ }^{48}$ linking such doubt to maladaptive psychological functioning and psychological distress. Moreover, "concern about mistakes" predicted significant distress among both athletes and controls (Table 4). However, in the two samples, the nature of possibly unhealthy perfectionistic concerns was somewhat different. While athletes' distress was related to "concern about mistakes," this facet did not reach significance among the controls. "Parental criticism" was more pronounced as accounting for overall distress among controls, but this facet just reached significance in the athlete sample. Such criticism has been found to be associated with a fluctuation in self-esteem, notably among young athletes ${ }^{49-53}$ and may in general, cause concern as inducing a pursuit of fulfilling external standards and approval. ${ }^{21}$ Because "parental criticism" is not related to significant distress, such previous findings are marginally supported.

Positive impacts of perfectionistic strivings (ie, personal standards) predicted below cutoff scores for significant psychological distress, but only among the controls. As for overall distress, "personal standards" did not reach statistical significance for either controls or athletes. These findings did not align with previous notions ${ }^{55}$ of the importance of functional perfectionism in the pursuit of high standards and expectations within high-performance contexts such as elite sports.
Female adolescents in the general population may be more prone to emotional distress than athletes. ${ }^{54,55}$ The multivariate analyses indicated that such overall distress was present among both controls and among athletes. However, being a female athlete almost tripled the odds ratio for belonging to the high scoring distress group (Table 5) given a concurrent, fourfold increase in the risk for perfectionistic concerns. Hence, it may be the case that competitive sport participation is unrelated to extreme psychological distress in the absence of perfectionistic concerns.

\section{Conclusion}

One major strength of the current study is the large and national representative samples of athletes and controls. On the other hand, the cross-sectional design prevents causal conclusions, and hence the current findings should be interpreted with caution. Moreover, the accounting of only about $20 \%$ of marked psychological distress and up to about $40 \%$ of the variance in overall distress points to a need to explore additional physiological, psychological and psychosocial variables in the future and preferably longitudinal designs. Such designs should cover the transition from adolescence to adulthood considering the fact that distress among adult elite athletes may rise to the same levels, as in the general population. ${ }^{4,45}$

Limitations aside, the results of the current study are encouraging, as the lower levels of psychological distress among young elite athletes point to possible protecting factors of even high-level competitive sports. Moreover, in both samples, the weaker association between eating problems and distress may indicate that such problems may not imply a psychological risk of developing severe clinical eating disorders. The results are also encouraging in terms of new hypotheses, notably to validate the finding that among controls, higher levels of physical activity may increase the risk of marked psychological distress in nonathletes, while lower levels of physical activity seem to increase this risk among athletes.

The overall findings point to the need to reduce maladaptive perfectionistic concerns. Notably, psychoeducational approaches may be appropriate to inform parents of nonathletes about the negative consequences of criticism. Moreover, there is a need to prevent the sources of marked distress, ie, the concern over mistakes and doubts about action. A feasible approach for coaches, teachers and parents may be to promote perfectionistic strivings and supportive feedback that facilitate resilience and well-being to counterbalance unhealthy competitions and the internalization of external demands. 


\section{Data sharing statement}

Data supporting the results are not currently available as they will be used in a forthcoming longitudinal study.

\section{Acknowledgments}

The publication charges for this article have been funded by a grant from the publication fund of UiT - the Arctic University of Norway.

\section{Disclosure}

The authors report no conflicts of interest in this work.

\section{References}

1. Malina RB, Bouchard C, Bar-Or O. Growth, Maturation, and Physical Activity. Champaign, IL: Human Kinetics; 2004.

2. Tamminen KA, Holt NL. A meta-study of qualitative research examining stressor appraisals and coping among adolescents in sport. $J$ Sports Sci. 2010;28(14):1563-1580.

3. Gouttebarge V, Frings-Dresen M, Sluiter J. Mental and psychosocial health among current and former professional footballers. Occup Med (Lond). 2015;65(3):190-196.

4. Crocker PRE, Hoar SD, McDonough MH, Kowalski KC, Niefer CB. Emotional experience in youth sport. In: Weiss M, editor. Developmental Sport and Exercise Psychology: A Lifespan Perspective. Morgan Town, WV: Fitness Information Technology; 2004:197-222.

5. Gerber M, Holsboer-Trachsler E, Pühse U, Brand S. Elite sport is not an additional source of distress for adolescents with high stress levels. Percept Mot Skills. 2011;112(2):581-599.

6. Bergeron MF, Mountjoy M, Armstrong N, et al. International Olympic Committee consensus statement on youth athletic development. $\mathrm{Br} J$ Sports Med. 2015;49(13):843-851.

7. Ursin H, Eriksen HR. The cognitive activation theory of stress. Psychoneuroendocrinology. 2004;29(5):567-592.

8. Pensgaard AM, Duda JL. Sydney 2000: the interplay between emotions, coping, and the performance of Olympic-level athletes. Sport Psychol. 2003;17(3):253-267.

9. Gulliver A, Griffiths KM, Mackinnon A, Batterham PJ, Stanimirovic R. The mental health of Australian elite athletes. J Sci Med Sport. 2015;18(3):255-261.

10. Schaal K, Tafflet M, Nassif H, et al. Psychological balance in high level athletes: gender based differences and sport-specific patterns. PLoS One. 2011;6(5):e19007.

11. Hill PL, Curran T. Multidimensional perfectionism and burnout: a meta-analysis. Pers Soc Psychol Rev. 2016;20(3):269-288.

12. Bakken A. Ungdata. National Results. NOVA Report 8/16. Oslo: NOVA; 2016. (in Norwegian).

13. Nordfjærn T, Flemmen G, Dahl H. Psychosocial factors related to mental distress among Norwegian adolescents. Int J Ment Health Promot. 2012;14(3):151-161.

14. Scraml K, Perski A, Grossi G, Simonsson-Sarnecki M. Stress symptoms among adolescents: the role of subjective psychosocial conditions, lifestyle, and self-esteem. J Adolesc. 2011;34(5):987-996.

15. Gould D, Maynard I. Psychological preparation for the Olympic Games. J Sports Sci. 2009;27(13):1393-1408.

16. Frost RO, Marten P, Lahart C, Rosenblate R. The dimensions of perfectionism. Cogn Ther Res. 1990;14(5):449-468.

17. Hewitt PL, Flett GL. Perfectionism in the self and social contexts: Conceptualization, assessment, and association with psychopathology. J Pers Soc Psychol. 1991;60(3):456-470.

18. Stoeber J, Gaudreau P. The advantage of partialling perfectionistic strivings and perfectionistic concerns: critical issues and recommendations. Pers Individ Differ. 2017;104:379-386.
19. Appleton PR, Hill AP. Perfectionism and athlete burnout in junior elite athletes: the mediating role of motivation regulations. J Clin Sport Psychol. 2012;6(2):129-145.

20. Crocker PRE, Gaudreu P, Mosewich AD, Kljajic K. Perfectionism and the stress process in intercollegiate athletes: examining the $2 \times 2$ model of perfectionism in sport competition. Int J Sport Psychol. 2014;45: 325-348.

21. Flett GL, Hewitt PL. When does conscientiousness become perfectionism? Curr Psychiatr. 2007;6(7):49-60.

22. Gotwals JK, Stoeber J, Dunn JG, Stoll O. Are perfectionistic strivings in sports adaptive? A systematic review of confirmatory, contradictory, and mixed evidence. Can Psychol. 2012;53(4):263-279.

23. Damian LE, Negru-Subtirica O, Stoeber J, Băban A. Perfectionistic concerns predict increases in adolescents anxiety symptoms: a three wave longitudinal study. Anxiety Stress Coping. 2017;30(5):551-561.

24. Rice KG, Ray ME, Davis DE, DeBlaere C, Ashby JS. Perfectionism and longitudinal patterns of stress for STEM majors: implications for academic performance. J Couns Psychol. 2015;62(4):718-731.

25. Ommundsen Y, Roberts G, Lemyre PN, Miller BW. Parental and coach support or pressure on psychosocial outcomes of pediatric athletes in soccer. Clin J Sport Med. 2006;16(6):522-526.

26. Koivula N, Hassmen P, Fallby J. Self-esteem and perfectionism in elite athletes: effects of competitive anxiety and self-confidence. Pers Individ Differ. 2002;32(5):865-875.

27. Stoeber J, Stoll O, Peschek E, Otto K. Perfectionism and achievement goals in athletes: relations with approach and avoidance orientations in mastery and performance goals. Psychol Sport Exerc. 2008;9(2): 102-121.

28. Madigan DJ, Stoeber J, Passfield L. Perfectionism and training distress in junior athletes: a longitudinal investigation. J Sports Sci. 2017;35(5):470-475.

29. Fairburn CG, Shafran R, Cooper Z. A cognitive behavioural theory of anorexia nervosa. Behav Res Ther. 1999;37(1):1-13.

30. Rosenvinge JH, Pettersen G. Epidemiology of eating disorders part II: an update with a special reference to the DSM-5. Adv Eat Disord Theory Res Pract. 2015;3(2):198-220.

31. Sundgot-Borgen J, Torstveit MK. Prevalence of eating disorders in elite athletes is higher than in the general population. Clin J Sport Med. 2004;14(1):25-32.

32. Martinsen M, Sundgot-Borgen J. Higher prevalence of eating disorders among adolescent elite athletes than controls. Med Sci Sports Exerc. 2013;45(6):1188-1197.

33. Stice E. Risk and maintenance factors for eating pathology: a metaanalytic review. Psychol Bull. 2002;128(5):825-848.

34. Machado BS, Goncalves S, Martins C, Hoek HW, Machado PP. Risk factors and antecedent life events in the development of anorexia nervosa. A Portuguese case-control study. Eur Eat Disord Rev. 2014;22(4): 243-251.

35. Strand BH, Dalgard OS, Tambs K, Rognerud M. Measuring the mental health status of the Norwegian population: a comparison of the instruments SCL-25, SCL-10, SCL-5 and MHI-5 (SF-36). Nord J Psychiatry. 2003;57(2):113-118.

36. Tambs K, Moum T. How well can a few questionnaire items indicate anxiety and depression? Acta Psychiatr Scand. 1993;87(5):364-367.

37. Ommundsen Y, Roberts GC, Lemyre PN, Miller B. Peer relationships in adolescent competitive soccer: associations to perceived motivational climate, achievement goals and perfectionism. J Sports Sci. 2005;23(9):977-989.

38. Gotwals JK, Dunn JGH, Dunn JC, Gamache V. Establishing validity evidence for the Sport Multidimensional Perfectionism Scale-2 in intercollegiate sport. Psychol Sport Exercise. 2010;11(6):423-432.

39. Garner DM. Eating Disorders Inventory-2: Professional Manual. Odessa, FL: Psychological Assessment Resources Inc.; 1991.

40. Clausen L, Rokkedal K, Rosenvinge JH. Validating the eating disorder inventory (EDI-2) in two Danish samples: a comparison between female eating disorder patients and females from the general population. Eur Eat Disord Rev. 2009;17(6):462-467. 
41. Beals KA, Manore MM. Disorders of the female athlete triad among collegiate athletes. Int J Sport Nutr Exerc Metab. 2002;12(3):281-293.

42. Lien L, Haavet OR, Dalgard F. Do mental health and behavioural problems of early menarche persist into late adolescence? A three-year follow-up study among adolescent girls. Soc Sci Med. 2010;71(3):529-533.

43. Mahoney JL, Stattin H. Leisure activities and adolescent antisocial behavior: the role of structure and social context. J Adolesc. 2000;23(2):113-127.

44. Fløtnes IS, Nilsen TIL, Augestad LB. Norwegian adolescents, physical activity and mental health: the Young-HUNT study. Nor Epidemiol. 2011;20(2):153-161.

45. Junge A, Feddermann-Demont N. Prevalence of depression and anxiety in top-level male and female football players. BMJ Open Sport Exerc Med. 2016;2(1):e000087.

46. Sundgot-Borgen J, Meyer NL, Lohmann TG, et al. How to minimise the health risks to athletes who compete in weight-sensitive sports review and position statement on behalf of the Ad Hoc Research Working Group on Body Composition, Health and Performance, under the auspices of the IOC Medical Commission. Br J Sports Med. 2013;47(16):1012-1022.

47. Neumark-Sztainer D, Wall M, Larson NI, Eisenberg ME, Loth K Dieting and disordered eating behavior from adolescence to young adulthood: findings from a 10-year longitudinal study. J Am Diet Assoc. 2011;111(7):1004-1011.
48. Gaudreau P, Thompson A. Testing a $2 \times 2$ model of dispositional perfectionism. Pers Individ Dif. 2010;48(5):532-537.

49. Dunn GHJ, Dunn JC, Gamache V, Holt NL. A person-oriented examination of perfectionism and slump-related coping in female intercollegiate volleyball players. Int J Sport Psychol. 2014;45(4):298-324.

50. Kaye M, Frith AL, Vosloo J. Dyadic anxiety in youth sport: the relationship of achievement goals with anxiety in young athletes and their parents. J Appl Sport Psychol. 2015;27(2):171-185.

51. McArdle S, Duda JK. Exploring the etiology of perfectionism and perceptions of self-worth in young athletes. Soc Dev. 2008;17(4): 980-997.

52. Sapieja KM, Dunn JGH, Holt NL. Perfectionism and perceptions of parenting styles in male youth soccer. $J$ Sport Exerc Psychol. 2011;33(1):20-39.

53. Flett GL, Hewitt PL. The perils of perfectionism in sports" revisited: toward a broader understanding of the pressure to be perfect and its impact on athletes and dancers. Int J Sport Psychol. 2014;45(4): 395-407.

54. Thapar A, Collishaw S, Pine D, Thapar AK. Depression in adolescence. Lancet. 2012;379(9820):1056-1067.

55. Remes $\mathrm{O}$, Brayne $\mathrm{C}$, Lafortune $\mathrm{L}$. The prevalence of anxiety disorders across the life course: a systematic review of reviews. Lancet 2014;384(special issue):S66.
Open Access Journal of Sports Medicine

\section{Publish your work in this journal}

The Open Access Journal of Sports Medicine is an international, peer-reviewed, open access journal publishing original research, reports, reviews and commentaries on all areas of sports medicine. The journal is included on PubMed. The manuscript management system is completely online and includes a very quick and fair

\section{Dovepress}

peer-review system. Visit http://www.dovepress.com/testimonials.php to read real quotes from published authors. 